\title{
Probabilistic Voltage Stability Assessment Considering Variability of Wind Power
}

\author{
Moumita Sarkar, Anca D. Hansen, Poul E. Sørensen \\ Department of Wind Energy \\ Technical University of Denmark \\ mosar@dtu.dk, anca@dtu.dk, posq@dtu.dk
}

\begin{abstract}
Traditional voltage stability assessment methods do not include temporal variation of renewable power generations like wind. This paper proposes a novel methodology for probabilistic voltage stability assessment methodology which can be used in conjunction with any of the existing traditional voltage stability indices. Historical wind power data are used to determine probabilistic distribution of wind power at future instant based on wind power value at current instant. Based on the probabilistic risk of increase and decrease of wind power at future instant, two probabilistic voltage stability indices are computed. The worse case value among the two indices are used as prediction of voltage stability index at future instant, based on current system parameters. Effectiveness of the proposed methodology in predicting proximity of the system voltage collapse is illustrated through case studies and time-series simulations. Results show that proposed methodology predicts more realistic proximity to voltage collapse than traditional stability assessments.
\end{abstract}

Index Terms-Probabilistic assessment, Reactive power support, Variability, Voltage stability, Wind power

\section{INTRODUCTION}

Concerns of climate change and energy security combined with reduction of prices of renewable power plants have led to increased penetration of converter based variable renewable generation in power systems worldwide. However because of inherent fluctuation and variability of the renewable energy sources, there are additional challenges in terms of power system security and stability. Voltage instability might be even more pronounced in power systems with large share of renewable generations. However, modern converter based renewable generations can also support largely in alleviating voltage stability problems [1].

IEEE/CIGRE Joint Task Force defines voltage stability as the "ability of a power system to maintain steady voltages at all buses in the system after being subjected to a disturbance from a given initial operating condition" [2]. Voltage instability in the system occurs in the form of progressive rise or fall of voltages at some buses. Voltage instability can lead to sequence of events that may trigger blackout or exceptionally low voltages in the system, these being known as voltage

This work is done as part of Security Assessment of Renewable Power Systems (SARP) project funded by Energinet under the Public Service Obligation scheme (Forskel 12427). collapse [2]. There have been several voltage instability related blackouts in history like, Denmark-Sweden black-out on September 23 in 2003, black-out in the southern part of Greece in 2004, voltage collapse in Poland in 2006 [3], [4]. To prevent system voltage collapse defence plans have been developed [5]. However, before activation of the actual defence plans, preventive operation measures like activation of capacitors, disconnection of shunt reactors, start up of generating units, adapting voltage setpoints of $\mathrm{MV} / \mathrm{HV}$ transformers, etc, are employed. In case operation measures are not sufficient in preventing degradation of voltage, defence plans are activated as last resort measures to prevent system black-out. Defence plans for prevention of voltage collapse includes measures like blocking of on-load tap changers (OLTC) and undervoltage load shedding [4], [6], [7].

Voltage stability assessment is often carried out to investigate the risks or proximity to voltage instability appearance, being thus a tool to prevent voltage collapse. Voltage stability indices (VSI) typically quantify measure of proximity to voltage collapse. In literature, many VSI have been developed, as listed by Cañizares et. al. in [8]. However, it is worth mentioning that all VSIs are proposed for systems which do not have large penetration of renewable energy generations. Traditionally voltage stability assessment is done considering changes in load [9]. However, with variable renewable energy generations like wind power plants (WPPs) in the power systems there is also temporal variation in power generation. Recent events like black-out in South Australia in 2016 [10] and disturbance in UK grid on August 9, 2019 [11] have been incited by large share of wind power in their respective power systems. Therefore it is important to include wind power in traditional voltage stability assessment methods. One of the main challenges of including wind power in VSI assessment methods is variability and fluctuation of wind power. Several studies, such as [1], [12], have shown that VSI of power system is improved when WPPs provide reactive power support. However, due to the continuous increasing of wind power penetration, probability of change in wind power needs to taken into consideration in order to perform voltage stability assessment in future power systems. This is even more significant when the power system is under stressed conditions, close to instability. In such circumstances, effect of wind power variations may move the system operating point beyond the stability margin. On the other hand, converter connected 
wind turbine generators have capability to provide reactive power support to alleviate voltage stress conditions. These factors motivates to develop VSI assessment method including wind power support and wind power fluctuations. Authors have quantified reactive power capability of wind power plants in [13] and studied impact of wind power fluctuations in [14].

The objective of this paper is to present a novel proposed probabilistic voltage stability assessment methodology to include uncertainty of wind power using existing VSI. Main contributions of this paper are: a) voltage stability assessment including maximum available reactive power support from wind power, and b) proposed novel probabilistic voltage stability assessment methodology to account for variability and fluctuation of wind power, which van be used in together with any of the existing traditional voltage stability indices. The proposed probabilistic voltage stability assessment methodology is demonstrated using existing voltage stability indices like, PV curves, minimum eigenvalue of system and load margin. Effectiveness of the proposed probabilistic voltage stability assessment in predicting proximity of the system voltage collapse is illustrated through time-series simulations.

This paper is organised as follows: Section II briefly describes some of the traditional indices for voltage stability assessment that are used in this paper. Section III presents the proposed methodology for probabilistic voltage stability assessment. In Section IV, the test system used in the present investigation together with wind turbine and wind power plant model are described. Results of the case studies are presented and discussed in Section V. Section VI concludes the paper.

\section{INDICES FOR Voltage StABILITY ASSESSMENT}

VSIs are used to assess proximity to voltage collapse at any operating point. There are many VSIs proposed in literature [15]. While some VSIs detect weakest bus or line in the system, some other VSIs can predict voltage collapse proximity of overall system. Objective of VSIs is to define a scalar magnitude which can be monitored as system parameter changes [8]. Therefore the trajectory of VSIs needs to be predictable and smooth, such that acceptable predictions can be made. In this paper existing traditional overall VSIs that can predict system collapse point are used. These VSIs are briefly described in the following subsections.

\section{A. Eigenvalue analysis}

Eigenvalue analysis for voltage instability evaluation was proposed Gao et. al in [16]. Eigenvalue decomposition of the Jacobian matrix can be written as in (1), if the Jacobian matrix is diagonalizable.

$$
J_{R}=\xi \Lambda \eta
$$

where,
$\Lambda=$ diagonal eigenvalue matrix of reduced Jacobian matrix, $J_{R}$
$\xi=$ right eigenvector matrix of $J_{R}$
$\eta=$ left eigenvector matrix of $J_{R}$

Each eigenvalue represents a mode of the system. Magnitude of each eigenvalue determines weakness of the corresponding mode. Smaller the magnitude of eigenvalue, weaker is the mode. The system collapses when the minimum eigenvalue of the system becomes zero.

\section{B. PV curves}

PV curves (also known as nose curves) show relation between active power transferred and the voltage at the receiving end [9], [17]. With increasing load demand, active power transferred increases until it reaches point of maximum power transfer (MPT) and then starts to decrease. The maximum power transfer value corresponds to the knee point of the PV curve. Beyond the knee point, voltage drops rapidly with increase in active power demand, causing voltage instability. The voltage corresponding to knee point is known as critical voltage.

\section{Loading Margin}

Loading margin of a system at a particular operating point is defined as the amount of additional load increase that would cause a voltage collapse [8]. Loading margin can be obtained from the distance of the operating point from the knee point on the PV curve. If load is assumed to have constant power factor, loading margin can be obtained from measure of only active load power. The system collapses when loading margin reduces to zero.

\section{Probabilistic Voltage Stability Assessment METHODOLOGY}

For voltage stability assessment of power systems with large number of WPPs besides change in load power, it is important to take into account variability in wind power generation. Wind is a variable source which causes variations in the power production from WPP. To account for uncertainty, probabilistic voltage stability assessment is proposed in this paper.

Wind speed changes between two consecutive time periods $t$ and $t+1$, which causes change in wind power production. If $P_{W, t}$ is the wind power production at $t$ time instant, $P_{W, t+1}$ can be either higher or lower than $P_{W, t}$. Statistical analysis of wind power data (measured or simulated) at $t+1$ instant, sorted according to wind power $P_{W, t}$ shows the probability distribution of possible changes in wind power at $t+1$ time instant.

$$
p=F\left(P_{W, t+1}\right)=\operatorname{Pr}\left(P_{W, t+1} \leq P_{W}\right)
$$

where, $p$ is the probability that $P_{W, t+1}$ is smaller than or equal to some value of wind power, $P_{W}$. This is illustrated in Fig. 1. All $P_{W, t+1}$ are sorted into a bin such that $P_{W, t} \in(a, b] . a$ and $b$ denote the edges of the bin. In Fig. 1, cumulative probability distribution of wind power at $t+1$ instant is shown when initial wind power, $P_{W, t} \in(0.6,0.7] \mathrm{pu}$. The per unit value is based on the nominal capacity of WPP.

Since wind power is continuous increasing variable, inverse of cumulative probability distribution expressed in (2), gives the value of $P_{W, t+1}$ if probability value $p$ is known, such that $F\left(P_{W, t+1}\right)$ is greater or equal to $p$.

$$
P_{W, t+1}=F^{-1}(p)=\inf \left\{P_{W} \in[0,1]: F\left(P_{W, t+1}\right) \geq p\right\}
$$




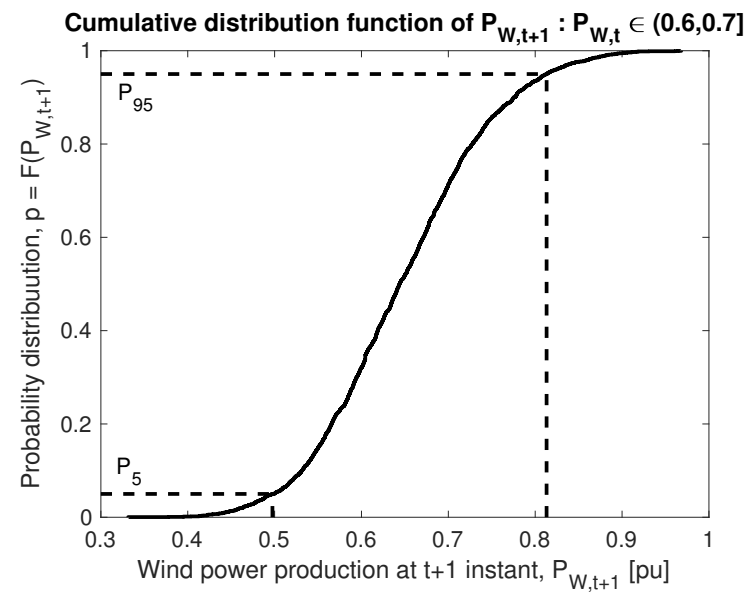

Fig. 1. Illustration of cumulative distribution function of possible values of wind power at $t+1$ instant when the wind power at instant $t$ lies with the interval $(0.6,0.7]$.

Since a set of $P_{W}$ satisfies the condition $F\left(P_{W, t+1}\right) \geq p$, lower bound of the set is considered. From (3) it can be observed that, $P_{W}$ lies within the the interval of $[0,1]$ which are the minimum and maximum value of possible wind power in per unit based on nominal capacity of WPP.

Fig. 1 shows that if present wind power lies within the interval $(0.6,0.7]$, there is 0.95 probability that wind power will remain below 0.81 pu and 0.05 probability that it can fall below $0.5 \mathrm{pu}$. In both cases VSI of the system will be affected. Depending on the network parameters increasing of wind power may decrease the VSI and vice-versa. To generalise the probabilistic voltage stability assessment methodology, risk of both increase and decrease in wind power are considered. Considering risk of increase in wind as $p_{u}$ and risk of decrease in wind as $p_{l}$, probabilistic values of wind power at $t+1$ instant can be derived from (3).

$$
P_{W, t+1, u}=\inf \left\{P_{W} \in[0,1]: F\left(P_{W, t+1}\right) \geq p_{u}\right\}
$$

and

$$
P_{W, t+1, l}=\inf \left\{P_{W} \in[0,1]: F\left(P_{W, t+1}\right) \geq p_{l}\right\}
$$

Considering a risk of $5 \%$, values of $p_{l}$ and $p_{u}$ can be set to 0.05 and 0.95 respectively. $p_{l}=0.05$ implies there is 0.05 probability that $P_{W, t+1} \leq P_{W, t+1, l}$. To include maximum possible deviations, of wind power risk can be set to $1 \%$, which implies $p_{l}=0.01$ and $p_{u}=0.99$.

Using the probabilistic values of wind power at $t+1$ instant, probabilistic voltage stability index (PVSI) corresponding to risk of increase and decrease in wind power are computed.

$$
P V S I_{u}=V S I: P_{W}=P_{W, t+1, u}
$$

and

$$
P V S I_{l}=V S I: P_{W}=P_{W, t+1, l}
$$

The probabilistic voltage stability assessment methodology proposed in this paper follows a conservative approach. There- fore between $P V S I_{u}$ and $P V S I_{l}$, the one depicting closer proximity to voltage collapse is taken as the PVSI.

$$
P V S I=\min \left(P V S I_{u}, P V S I_{l}\right)
$$

In other words, PVSI predicts worse case VSI at future instant.

The methodology proposed in this paper emphasises on voltage stability assessment considering variability of wind power. Any existing VSI (as described in Section II) can be used in conjunction with the proposed methodology to assess the impact of wind power variability on voltage stability of the system. With increase in stochastic generation sources, this methodology could be used by transmission system operators for security assessment studies, together with traditional VSIs. Regarding computational burden of the methodology, it can be implemented in two phases, offline and online.

\section{A. Offline phase}

Offline phase requires pre-processing of measured or simulated wind power data at WPP location. Since wind speed varies according to geographical location as well as meteorological conditions, probability distribution of wind power (derived from wind speed) is WPP location specific. Data for each WPP needs to be assessed distinctly. This can be done offline and stored in lookup tables. To illustrate, probability distribution matrix of wind power at an offshore location in North Sea is shown in Fig. 2. One year data at resolution of

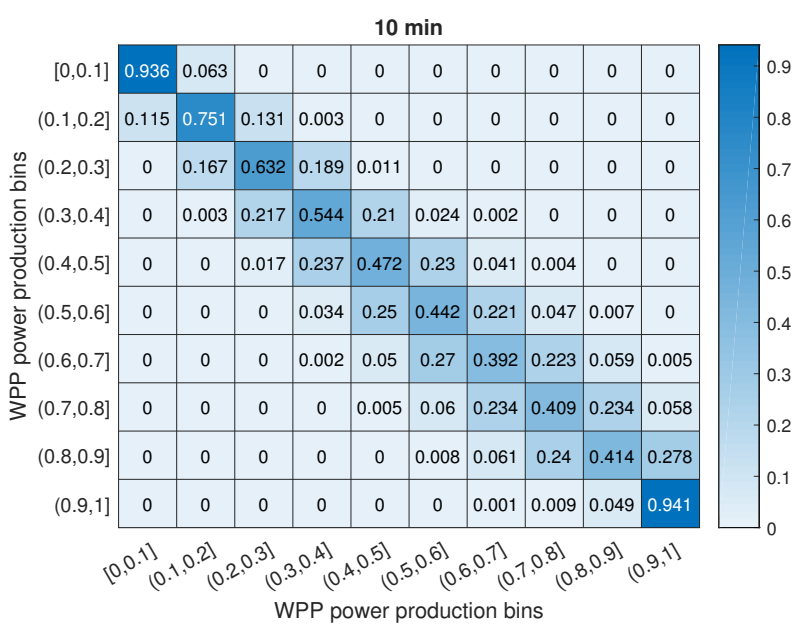

Fig. 2. Probability distribution matrix of wind power data at resolution of 10 minutes. Wind power data has been binned into 10 bins, each of width 0.1 pu.

10 minutes has been used to obtain the probability distribution matrix. The complete data set is binned into 10 bins, each of width $0.1 \mathrm{pu}$ (on nominal capacity of WPP), to obtain the probability distribution matrix. It can be observed that the probability distribution is concentrated along the diagonal of the matrix. This is expected since the probability of wind power to stay in the current state is high in 10 min interval. Depending on the time interval of study, resolution of data can be chosen. Probability distribution of wind power will vary if a higher or lower study time interval is chosen. To illustrate 
this, probability distribution matrix of wind power at the same location but at resolution of 30 minutes is shown in Fig. 3 . Diagonal of the probability distribution matrix in Fig. 3 is

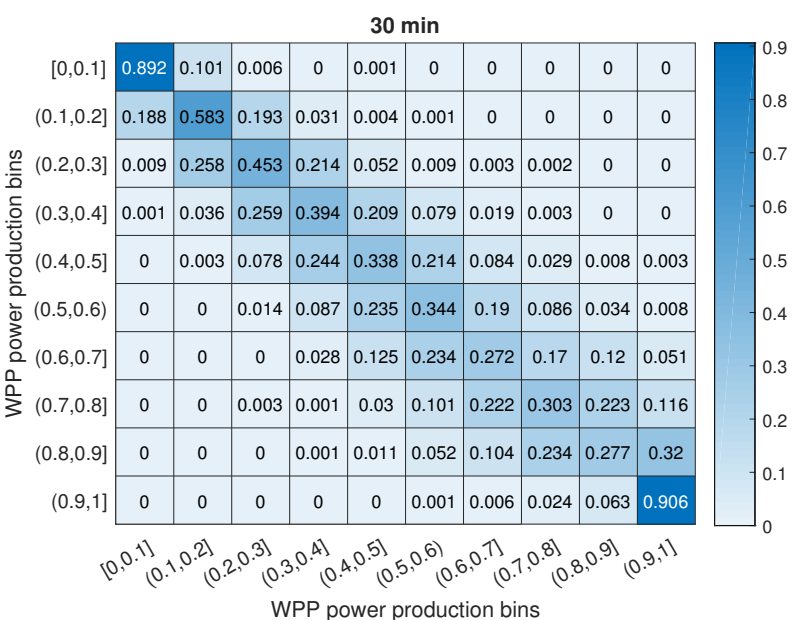

Fig. 3. Probability distribution matrix of wind power data at resolution of 30 minutes. Wind power data has been binned into 10 bins, each of width 0.1 pu.

spread widely as compared to Fig. 2. The reason for this is the variability of wind power in the considered location in $30 \mathrm{~min}$ interval. In $30 \mathrm{~min}$, the probability of changing the current wind speed is evenly spread in all neighbouring bins. Therefore, based on time interval study, appropriate probability distribution needs to be chosen.

\section{B. Online phase}

Online phase involves PVSI calculation based on current operating conditions. Based on system variables at instant $t$, VSI is estimated for worse case scenario at $t+1$ instant. This phase requires two PVSI calculations corresponding to risk of increase of wind power and risk of decrease of wind power. The two values are then compared to obtain the worse case PVSI.

\section{TEST System}

\section{A. Wind Turbine and Wind Power Plant Model}

A 360 MW aggregated WPP is considered in this paper. The WPP model as shown in Fig. 4, consists of a single WT together with equivalent impedance of aggregated power collection system [18]. Full rated converter based Type 4A

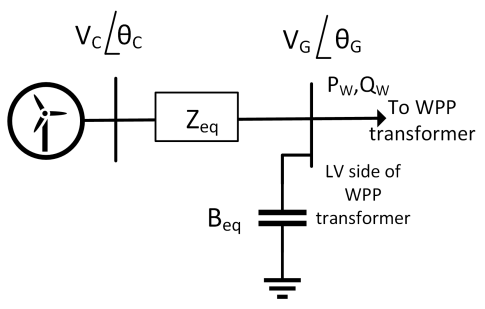

Fig. 4. Aggregated WPP model [13]

WT model as defined by IEC standard 61400-27-1 [19], [20] is used in this paper. Reactive power support from WPP is obtained by operating the WPP in "Q control" mode [21], which ensures reactive power control independent of active power. In this paper, to utilise maximum reactive power availability, WPP is are operated at maximum reactive power capability which is is both active power production and grid voltage dependent. The reactive power capability model of WPP is modelled based on work done by authors in [13]. Reactive power capability of converter connected Type 4 WTs can be either converter voltage limited or converter current limited. At WPP level, converter voltage limited reactive power and converter current limited reactive power can be defined by (9) and (10) respectively.

$$
\begin{gathered}
Q_{V}=\sqrt{\left(\frac{V_{G} V_{C}}{\left|\overline{Z_{e q}}\right|}\right)^{2}-\left(P_{W}+\frac{V_{G}^{2} R_{e q}}{\left|\overline{Z_{e q}}\right|^{2}}\right)^{2}}-\frac{V_{G}^{2} X_{e q}}{\left|\overline{Z_{e q}}\right|^{2}} \\
Q_{I}=\sqrt{\left(V_{G} I_{C}^{\text {max }}\right)^{2}-P_{W}^{2}}
\end{gathered}
$$

where,

$V_{G}=$ grid voltage at point of connection of WPP

$V_{C} \quad=$ maximum allowable converter voltage $\left(V_{C}=V_{C}^{\max }\right.$, for maximum injection capability $V_{C}=V_{C}^{\text {min }}$, for maximum absorption capability)

$I_{C}^{\max }=$ maximum allowable converter current

$P_{W} \quad=$ active power production from WPP

$\overline{Z_{e q}}=R_{e q}+j X_{e q}$, sum of impedance of aggregated collection system cables, individual WTs and WT transformers

Maximum reactive power injection capability of WPP is obtained from (11).

$$
Q_{l i m}=\min \left(Q_{V}, Q_{I}\right)+B_{e q} V_{G}^{2}
$$

where

$$
B_{e q}=\begin{aligned}
& \text { equivalent shunt susceptance of collection system } \\
& \text { cables }
\end{aligned}
$$

Fig. 5 illustrates WPP reactive power capability characteristics. The solid lines in Fig. 5 represent reactive power injection

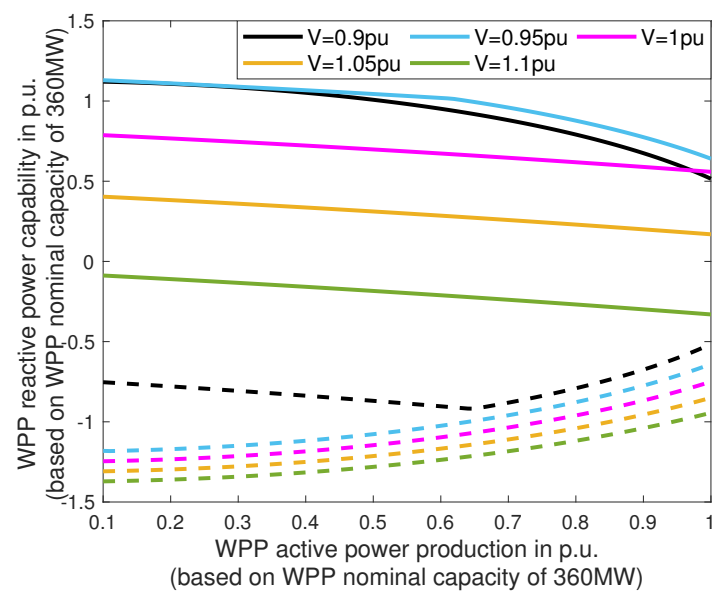

Fig. 5. Voltage and active power dependent reactive power capability curves of the WPP 
capability. Dotted lines represent reactive power absorption capability of the WPP. If the voltage at WPP connection point is maintained constant by an OLTC transformer, reactive power capability of WPP reduces with increase in wind power production. In the considered test system, the WPP is connected to the transmission grid through an OLTC transformer such that the WPP side voltage is maintained at 1 p.u.

Stochastic wind power time series data for one year is simulated using CorRES (Correlations in Renewable Energy Sources) software which has been developed at Technical University of Denmark, Department of Wind Energy [22] [24].

\section{B. Power System}

A simple test system, as shown in Fig. 6, is considered for the case study. The test system comprises of a synchronous generator representing the external power system, a load and an aggregated wind WPP model which is connected to the power system through an OLTC transformer. This test system is based on typical WPP connection to transmission grid as illustrated in [25]. Parameters of the test system are given in Table I. Since steady-state studies are performed in

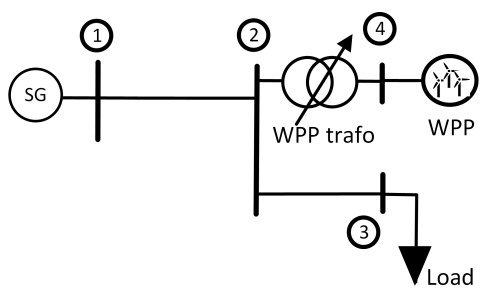

Fig. 6. Test system model

TABLE I

Test System Parameters

\begin{tabular}{|c|c|}
\hline Parameter & Value \\
\hline Synchronous Generator Rating & $1000 \mathrm{MVA}$ \\
\hline WPP Rating & $360 \mathrm{MW}$ \\
\hline Load Power Factor & 0.9 \\
\hline
\end{tabular}

this paper, dynamic components of synchronous generators, like, governor, exciter and power system stabiliser are not modelled. Parameters for OLTC transformer are given in Table II. Probability of variation of load at $t+1$ instant has not been

TABLE II

OLTC TRANSFORMER PARAMETERS

\begin{tabular}{|c|c|}
\hline Parameter & Value \\
\hline Maximum transformer ratio, $r_{\max }$ & 1.1 \\
\hline Minimum transformer ratio, $r_{\max }$ & 0.85 \\
\hline Per tap change, $\Delta r$ & 0.01 \\
\hline Deadband & \pm 0.01 \\
\hline
\end{tabular}

considered in this paper.

\section{RESULTS AND DISCUSSION}

\section{A. Voltage stability assessment with wind power}

In the following case studies, impact of variation of wind power without and with maximum reactive power support from WPP is studied. Four different scenarios of combination of active and reactive power support from WPP are considered.

Case 1: $P_{W}=0, Q_{W}=0$

Case 2: $P_{W}=P_{\max }, Q_{W}=0$

Case 3: $P_{W}=P_{\max }, Q_{W}=Q_{\max }$

Case 4: $P_{W}=0, Q_{W}=Q_{\max }$

Case 1 represents that no WPP is connected to the system. Case 2 and Case 3 depict maximum wind power production without and with reactive power support from WPP respectively. Case 4 corresponds to the scenario when WPP provides maximum reactive power support even though there is no wind power production. This case is similar to emulating WPP as static synchronous compensator (STATCOM).

For these case studies, load is increased to study the impact on VSIs. Fig. 7 shows characteristic of PV curve of load bus, minimum eigenvalue of the system and system load margin with increased loading. It can be observed that with increased loading, system moves closer to voltage collapse. In this paper constant power factor load is assumed. Therefore, increased loading is represented by increase in active load power. It can be observed from Fig. 7a that for Case 1 MPT is reached at $720 \mathrm{MW}$. For Case 2 when WPP is producing maximum wind power, MPT increases to $800 \mathrm{MW}$, even though there is no reactive power support from WPP. This is due to the mid point location of WPP in the test system. Wind power production reduces loading of the line connecting bus 1 and 2 in Fig. 6, resulting in increased MPT. In Case 3 when WPP is producing maximum wind power as well as providing maximum available reactive power to the system, MPT increases to $880 \mathrm{MW}$. In Case 4, when WPP is behaving as STATCOM, MPT is $830 \mathrm{MW}$ which is better than Case 1 and Case 2. Similar results can be observed in Fig. 7b. Minimum eigenvalue improves with inclusion of WPP in the system. Further betterment is observed, with reactive power support from WPP. Voltage collapse occurs in the system when minimum eigenvalue reaches zero. The system is on the verge of voltage collapse below minimum eigenvalue of 0.4. In Fig. 7c, it can be observed that for the test system, load margin is smooth and linear. At any loading, there is a clear improvement in load margin with reactive power support from WPP. If maximum reactive power support from WPP is utilised regardless of wind power production, load margin will vary between the load margins for Case 3 and Case 4 depending on the load values.

\section{B. Probabilistic voltage stability assessment}

To calculate PVSI load power is assumed to be constant at $800 \mathrm{MW}$ while wind power production is varied from 0 to 360 MW which is the nominal capacity of the WPP under study. From Fig. 7c it can be observed that load value of $800 \mathrm{MW}$ represents stressed operating point. The wind power 


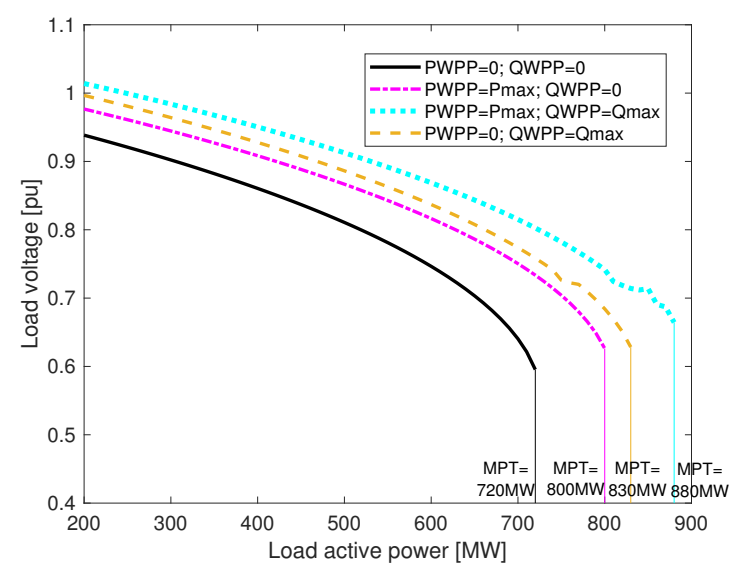

(a) PV curve

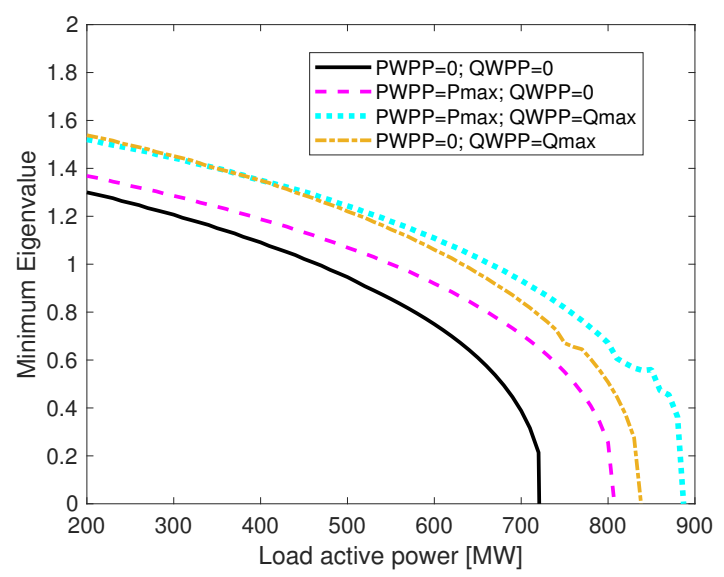

(b) Minimum eigenvalue

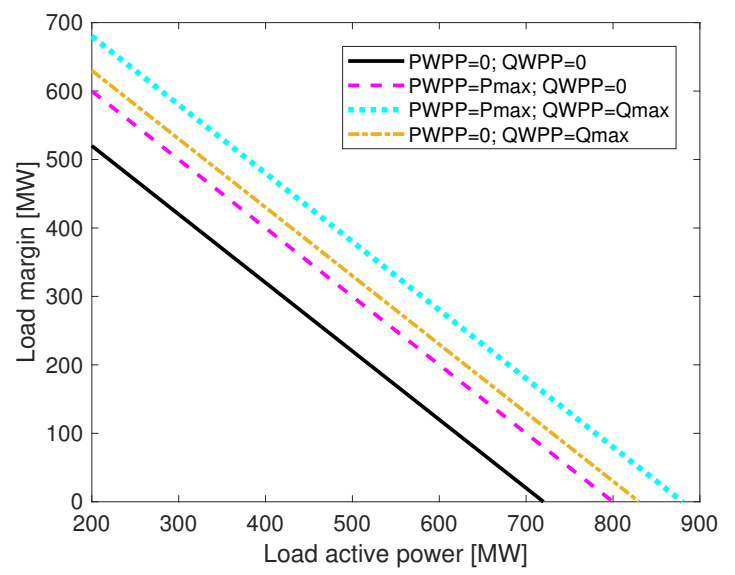

(c) Load margin

Fig. 7. Voltage stability indices for four scenarios : (i) WPP disconnected (ii) WPP producing nominal power, no reactive power support from WPP (iii) WPP producing nominal power, maximum reactive power support from WPP (iv) WPP producing no power, maximum reactive power support from WPP

series at resolution of 10 minutes is considered. The data is sorted into 10 bins of width $0.1 \mathrm{pu}$ (on nominal capacity of WPP). Pre-processed probability distribution matrix shown in
Fig. 2 is used to calculate 5\% risk in increase and decrease of wind power for each bin. The WPP is controlled such that WPP provides maximum available reactive power to the grid. Fig. 8 shows comparison of VSI vs PVSI in case of load

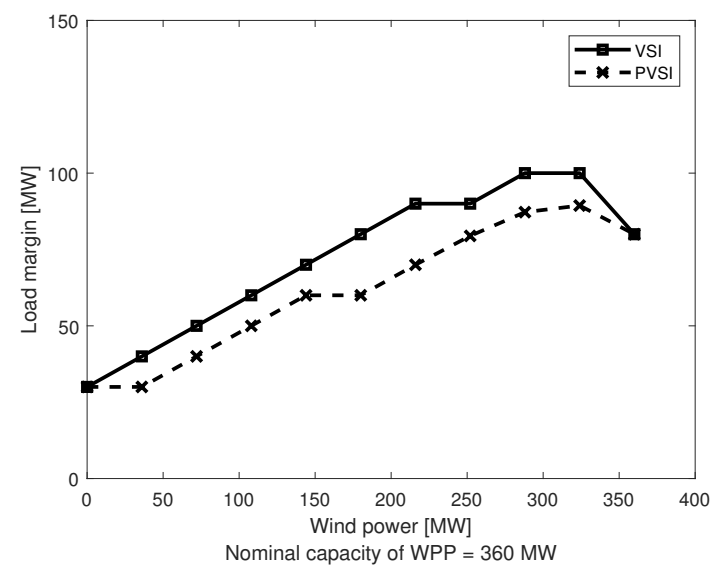

Fig. 8. Load margin vs wind power with reactive power support from WPP

margin. Since PVSI is either less than or equal to VSI, it gives an intentional conservative estimation of proximity to voltage collapse. For the test system used in this case study, PVSI decreases with decrease in wind power although reactive power capability of WPP increases (as seen in Fig. 5).

Time-series simulation of the proposed methodology to predict PVSI is shown in Fig 9. It can be observed from
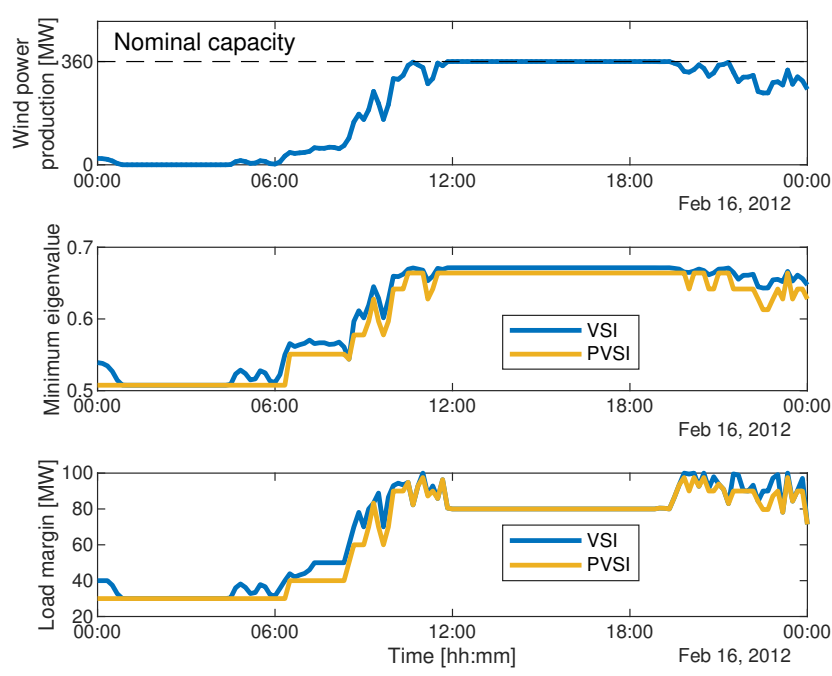

Fig. 9. Comparison of time series simulation of voltage stability indices with probabilistic voltage stability assessment approach

Fig. 9 that fluctuations in wind power production result in fluctuations in VSI (minimum eigenvalue and load margin). For both minimum eigenvalue and load margin, PVSI is able to predict worse case change in VSI. PVSI is always less than or equal to VSI, therefore giving conservative approximation 
of proximity to voltage collapse. It can be observed that not including uncertainty of wind power can lead to calculation of incorrect VSI, which may not reflect actual proximity of the system to voltage collapse. Using PVSI, threshold for corrective measures could be set up to prevent voltage collapse.

\section{CONCLUSION}

This paper presents voltage stability assessment including maximum reactive power support from wind power plants. To account for temporal variations in wind power, a novel probabilistic voltage stability assessment methodology is proposed using the existing traditional VSI. The results have shown that reactive power support from WPP improves stability index of the system. Regardless of variability of of wind power, maximum available reactive power support from of WPPs helps in alleviating voltage stability margin. Probabilistic voltage stability index shows that not considering variability of wind power can lead to overestimation of proximity to voltage collapse. The proposed methodology predicts realistic stability index at future instant based on current system parameters, as seen from the result of time-series simulations. It is worth mentioning that the presented methodology is generic for any variable renewable energy sources. The proposed methodology can provide system operators new insights into the possibility to set up corrective measures to prevent voltage collapse in power system with high share of renewable power generations.

\section{REFERENCES}

[1] T. Souxes, I.-M. Granitsas, and C. Vournas, "Effect of stochasticity on voltage stability support provided by wind farms: Application to the hellenic interconnected system," Electric Power Systems Research, vol. 170, pp. 48-56, 2019

[2] P. Kundur, J. Paserba, V. Ajjarapu, G. Andersson, A. Bose, C. Canizares, N. Hatziargyriou, D. Hill, A. Stankovic, C. Taylor et al., "Definition and classification of power system stability," IEEE transactions on Power Systems, vol. 19, no. 2, pp. 1387-1401, 2004.

[3] G. Andersson, P. Donalek, R. Farmer, N. Hatziargyriou, I. Kamwa P. Kundur, N. Martins, J. Paserba, P. Pourbeik, J. Sanchez-Gasca et al. "Causes of the 2003 major grid blackouts in north america and europe, and recommended means to improve system dynamic performance," IEEE transactions on Power Systems, vol. 20, no. 4, pp. 1922-1928, 2005.

[4] European Network of Transmission System Operators of Electricity, "Technical background and recommendations for defence plans in the continental Europe synchronous area," Tech. Rep., 2011.

[5] K. Das, P. Sorensen, A. D. Hansen, and H. Abildgaard, "Integration of renewable generation in power system defence plans," $P h D$ dissertation, 2016.

[6] K. Das, A. D. Hansen, and P. E. Sørensen, "Aspects of relevance of wind power in power system defense plans," in 12th International Workshop on Large-Scale Integration of Wind Power into Power Systems as well as on Transmission Networks for Offshore Wind Power Plants. Energynautics GmbH, 2013.

[7] S. De Boeck, D. Van Hertem, K. Das, P. E. Sørensen, V. Trovato, J. Turunen, and M. Halat, "Review of defence plans in europe: current status, strengths and opportunities," CIGRE Science \& Engineering, vol. 5, pp. 6-16, 2016.

[8] C. A. Canizares et al., "Voltage stability assessment: concepts, practices and tools," IEEE/PES power system stability subcommittee special publication, no. SP101PSS, 2002.

[9] T. Van Cutsem and C. Vournas, Voltage stability of electric power systems. Springer, 2007.
[10] R. Yan, T. K. Saha, F. Bai, H. Gu et al., "The anatomy of the 2016 south australia blackout: A catastrophic event in a high renewable network," IEEE Transactions on Power Systems, vol. 33, no. 5, pp. 5374-5388, 2018.

[11] National Grid UK, "Interim Report into the Low Frequency Demand Disconnection (LFDD) following Generator Trips and Frequency Excursion on 9 Aug 2019," Tech. Rep., 2019.

[12] J. M. García, "Voltage Control in Wind Power Plants with Doubly Fed Induction Generator," 2015, PhD. Thesis.

[13] M. Sarkar, M. Altin, P. E. Sørensen, and A. D. Hansen, "Reactive power capability model of wind power plant using aggregated wind power collection system," Energies, vol. 12, no. 9, p. 1607, 2019.

[14] M. Sarkar, M. J. Koivisto, M. Altin, and P. E. Sørensen, "Impact of power fluctuations in reactive power capability of wind power plants," in Cigre Aalborg 2019: International Symposium, 2019.

[15] J. Modarresi, E. Gholipour, and A. Khodabakhshian, "A comprehensive review of the voltage stability indices," Renewable and Sustainable Energy Reviews, vol. 63, pp. 1-12, 2016.

[16] B. Gao, G. Morison, and P. Kundur, "Voltage stability evaluation using modal analysis," IEEE transactions on power systems, vol. 7, no. 4, pp $1529-1542,1992$.

[17] P. Kundur, N. J. Balu, and M. G. Lauby, Power system stability and control. McGraw-hill New York, 1994, vol. 7.

[18] E. Muljadi, C. Butterfield, A. Ellis, J. Mechenbier, J. Hochheimer, R. Young, N. Miller, R. Delmerico, R. Zavadil, and J. Smith, "Equivalencing the collector system of a large wind power plant," in 2006 IEEE Power Engineering Society General Meeting. IEEE, 2006, pp. 9-pp.

[19] IEC 61400-27-1: Electrical simulation models - Wind Turbines, Std., February, 2015.

[20] K. Das, A. D. Hansen, and P. E. Sørensen, "Understanding iec standard wind turbine models using simpowersystems," Wind Engineering, vol. 40, no. 3, pp. 212-227, 2016

[21] Energinet, "Technical regulation 3.2 .5 for wind power plants with a power output above $11 \mathrm{~kW}, " 2015$. [Online]. Available: http://energinet.dk/

[22] P. Sørensen, A. D. Hansen, and P. A. C. Rosas, "Wind models for simulation of power fluctuations from wind farms," Journal of wind engineering and industrial aerodynamics, vol. 90, no. 12-15, pp. 13811402, 2002.

[23] E. Nuño, P. Maule, A. Hahmann, N. Cutululis, P. Sørensen, and I. Karagali, "Simulation of transcontinental wind and solar pv generation time series," Renewable energy, vol. 118, pp. 425-436, 2018.

[24] M. Koivisto, K. Das, F. Guo, P. Sørensen, E. Nuño, N. Cutululis, and P. Maule, "Using time series simulation tool for assessing the effects of variable renewable energy generation on power and energy systems," Wiley Interdisciplinary Reviews: Energy and Environment, p. e329, 2019.

[25] C. Vournas, I. Anagnostopoulos, and T. Souxes, "Transmission support using wind farm controls during voltage stability emergencies," Control Engineering Practice, vol. 59, pp. 100-110, 2017. 